\author{
M. Wadsworth $\cdot$ S. Butterworth $\cdot$ M. Marmot • \\ R. Ecob $\cdot$ R. Hardy
}

\title{
Early growth and type 2 diabetes: evidence from the 1946 British birth cohort
}

Received: 11 February 2005 / Accepted: 3 August 2005 / Published online: 11 November 2005

(C) Springer-Verlag 2005

\begin{abstract}
Aims/hypothesis: We assessed whether low birthweight or early adiposity rebound was more strongly associated with type 2 diabetes, and whether any effect of low birthweight or early adiposity rebound was explained by adult BMI, adult height, social class of subject or of his/her father, or maternal or paternal diabetes. Methods: Cox's proportional hazard models were used on data from the National Birth Cohort Study (the MRC National Survey of Health and Development), which was begun in 1946 and had self-reported physician-diagnosed diabetes with age at onset ranging from 31 to 53 years ( $n=78$ cases, and $n=47$ cases in the multivariate analysis) as the outcome. Results: A U-shaped association between birthweight and type 2 diabetes rates was close to statistical significance (quadratic term $p$ value $=0.08$ ). Younger age at adiposity rebound was associated with increased rates of type 2 diabetes (test for trend $p=0.002$ ), the association being robust to adjustment for each of sex, birthweight, weight at 2 years, father's social class, parental diabetes, and own social class. The effect of early adiposity rebound was very slightly reduced by adjustment for sex and adult height ( $p=0.003)$, but considerably reduced after adjustment for sex and adult BMI (test for trend $p=0.1$ ), and further reduced $(p=0.4)$ after additional adjustment for birthweight, weight at 2 years, adult height, social class of subject and of his/her father, and parental diabetes. Conclusions/interpretation: Early adiposity rebound was associated with an increased rate of type 2 diabetes inde-
\end{abstract}

M. Wadsworth $(\bowtie) \cdot$ S. Butterworth $\cdot$ R. Ecob $\cdot$ R. Hardy MRC National Survey of Health \& Development,

Department of Epidemiology \& Public Health, University College London Medical School,

London, UK

e-mail: m.wadsworth@nshd.mrc.ac.uk

Tel.: +44-20-76791734

Fax: +44-20-78130280

M. Marmot

Department of Epidemiology \& Public Health,

University College Medical School,

London, UK pendently of birthweight, but its effect was mostly through high adult BMI. Parental diabetes and possibly low weight at 2 years were also risks.

Keywords Adiposity rebound - Birthweight .

Early growth $\cdot$ Parental diabetes $\cdot$ Type 2 diabetes

\section{Introduction}

The association between low birthweight and type 2 diabetes is well documented [1-3], and may reflect the continuation of changes in glucose and insulin metabolism that occur during slow growth in utero [4]. Eriksson et al (2003) showed that type 2 diabetes was not only strongly associated with poor prenatal growth, but also with early postnatal growth [5]. Typically, early postnatal weight loss is followed by increased BMI at about 6 years of age. This is known as adiposity rebound, and early age at adiposity rebound has been suggested as a risk for adult obesity [6]. Eriksson et al (2003) found that early adiposity rebound was a risk for type 2 diabetes, but no adjustment could be made for adult obesity [5].

Growth in utero, and BMI in adolescence and adulthood, are also influenced by parental social class [7], and type 2 diabetes has been shown to be inversely associated with socio-economic status [8]. Few studies to date have controlled for the effect of obesity on the social gradient of risk of type 2 diabetes [9].

Parental diabetes is a complicating factor in the relationship between early growth and risk of type 2 diabetes. Birthweight tends to be low in the presence of paternal type 2 diabetes, and high in the presence of maternal diabetes [10]. Furthermore, type 2 diabetes is likely to have a genetic component [11], for which parental diabetes may be a marker.

In this paper we used prospectively collected data from a nationally representative birth cohort study, the MRC National Survey of Health and Development, to assess whether low birthweight or early adiposity rebound was more strongly associated with increased risk of type 2 
diabetes. We went beyond the scope of Eriksson et al [5] by also asking whether such an association pertained after having adjusted for adult BMI. We also examined whether any effect of low birthweight or early adiposity rebound on diabetes could be explained, or was modified by, social class of subject and of his/her father, or by diabetes in either parent.

\section{Materials and methods}

The sample The National Survey of Health and Development is a national prospective cohort study of 2547 women and 2815 men, followed up regularly since birth in March 1946, with high contact rates in childhood and adulthood, and a representative sample in both childhood and adulthood [12].

The outcome Cases of type 2 diabetes were identified by age at onset, using reports made at three home visits at age 36,43 and 53 years of age, and from response to a postal questionnaire at 31 years. This material was able to indicate that a cohort member had had an onset of physiciandiagnosed diabetes at or after 31 years of age (up to age 53). Altogether 78 cases were identified.

Growth measures Birthweight rounded to the nearest quarter of a pound was extracted from medical records within a few weeks of delivery and converted into kilograms. Weight $(\mathrm{kg})$ and height $(\mathrm{cm})$ were measured at most further contacts to date. In this analysis we used weight and height at 2, 4, 7, 11, 15, 26, 36, 43 and 53 years to calculate BMI (weight/height ${ }^{2}$ ). Age at adiposity rebound was defined as the age with lowest BMI for the ages 2, 4, 7 and 11 years.

Social measures Childhood social class was determined from father's occupation when the cohort member was aged 7 years, or if unavailable, father's social class at age 4 or

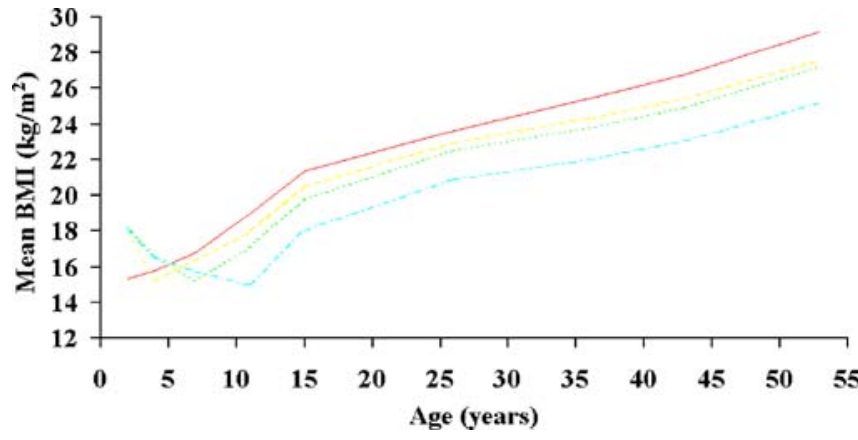

Fig. 1 Mean BMI according to age at adiposity rebound. Age at adiposity rebound: unbroken line, 2 years; broken line, 4 years; dotted line, 7 years; dashed and dotted line, 11 years

15 years. Adult social class was derived from reports of own main occupation at ages $26,36,43$ and 53 years.

Parental diabetes Information on parental diabetes was elicited at age 43 years by asking, 'Did your mother/father have diabetes?' There is no information on age at onset or type of treatment, so it is impossible to say whether parental diabetes was type 1 or type 2 diabetes. Some cases of maternal diabetes may have been gestational diabetes.

Ethical approval This was given by the London area Multi Centre Research Ethics Committee, most recently for the data collection at age 53 years. Cohort members gave informed consent for every aspect of the data collection procedure.

\section{Analysis}

Follow-up was in months from age 31 years until diagnosis of type 2 diabetes or last completed questionnaire. Of the initial 5362 cohort members, 1428 were excluded from analyses because they had died $(n=305)$, emigrated
Table 1 Rate of type 2 diabetes by birthweight and age at adiposity rebound

\footnotetext{
${ }^{\mathrm{a}}$ Birthweight as a continuous variable in kilograms and centred at $3.5 \mathrm{~kg}$
}

\begin{tabular}{lllll}
\hline Growth factor $(n)$ & $\begin{array}{l}\text { Rate (per 100,000 } \\
\text { person-years) }\end{array}$ & $\begin{array}{l}\text { Number of type 2 } \\
\text { diabetes cases }\end{array}$ & $\begin{array}{l}\text { Hazard ratio } \\
(95 \% \mathrm{CI})\end{array}$ & $p$ value \\
\hline $\begin{array}{l}\text { Birthweight (3921) } \\
\leq 3 \mathrm{~kg}(829)\end{array}$ & 50.9 & 21 & $1.00(0.47,2.12)$ & 0.4 \\
$3.0-3.5 \mathrm{~kg}(1398)$ & 31.5 & 22 & $0.61(0.29,1.29)$ & \\
$3.6-4.0 \mathrm{~kg}(1287)$ & 39.2 & 25 & $0.77(0.37,1.61)$ & \\
$\geq 4 \mathrm{~kg}(407)$ & 49.9 & 10 & 1.00 & \\
Linear (kg) & & 78 & $0.95(0.63,1.42)$ & 0.8 \\
Quadratic (kg $)^{\mathrm{a}}$ & & & $1.45(0.96,2.18)$ & 0.08 \\
Age at adiposity rebound & & & & \\
$(2240)$ & 99.6 & 12 & $4.63(1.04,20.68)$ & 0.01 \\
2 years (241) & 48.6 & 18 & $2.25(0.52,9.69)$ & \\
4 years (742) & 17 & $1.47(0.34,6.36)$ & \\
7 years (1063) & 20.8 & 2 & 1.00 & \\
11 years (194) & 49 & & \\
Trend per category & 39.9 & 78 & & \\
Total (3934) & & & & \\
\hline
\end{tabular}


Table 2 Birthweight and postnatal growth and shape in relation to adiposity rebound

$n=2240$ for weight and BMI at 2 years and BMI at 11 years; $n=2233$ for birthweight and change in weight

\begin{tabular}{lccccc}
\hline & \multicolumn{7}{c}{ Age at adiposity rebound (years) } & \\
\cline { 2 - 5 } & 2 & 4 & 7 & 11 & $p$ value \\
\hline Mean birthweight $(\mathrm{kg})$ & 3.37 & 3.43 & 3.40 & 3.31 & 0.03 \\
Mean weight at 2 years $(\mathrm{kg})$ & 12.03 & 13.02 & 12.97 & 12.83 & $<0.001$ \\
Mean change in $Z$-score of & -0.571 & -0.024 & -0.017 & 0.057 & $<0.001$ \\
weight from birth to 2 years & & & & & \\
Mean BMI at 2 years $\left(\mathrm{kg} / \mathrm{m}^{2}\right)$ & 15.32 & 18.01 & 18.14 & 18.00 & $<0.001$ \\
Mean BMI at 11 years $\left(\mathrm{kg} / \mathrm{m}^{2}\right)$ & 18.94 & 17.91 & 17.07 & 14.99 & $<0.001$ \\
\hline
\end{tabular}

$(n=421)$ or completed their last questionnaire $(n=702)$ before age 31 years, leaving 3934 eligible for analysis. First, rates of type 2 diabetes were calculated for each birthweight group and each age-at-adiposity-rebound group. Cox's proportional hazards models were used to examine the association between birthweight and between age at adiposity rebound and type 2 diabetes, unadjusted on all available cases. Mean birthweight, weight at 2 years, and mean BMI at 2 and 11 years were then compared across the four age-at-adiposity-rebound groups, to ensure validity of the rebound measure as a summary of growth trajectories in childhood. Then further proportional hazard models were used to examine age at adiposity rebound, adjusting separately for birthweight, weight at 2 years, father's social class, maternal diabetes, paternal diabetes, adult social class, adult BMI and adult height, and then for all factors. Adult social class, BMI and height were modelled as time-updated covariates, where the last available measure was used (either age 26, 36, 43 or 53 years) for each individual at risk at the time of each diabetes event. Only cases $(n=1786$, cases $=47)$ with complete data were used in these models and all analyses were adjusted for sex. The assumption of proportional hazards was checked by inspection of plots and by the use of time-dependent covariates, and was found to hold for all variables. Interactions were tested in the model to see whether any effect of adiposity rebound was modified by adult BMI, or parental diabetes. An additional model was run, omitting maternal and paternal diabetes, to see whether parental diabetes influenced the estimates of the other variables in the final model.

\section{Results}

Cohort members with a birthweight of $3 \mathrm{~kg}$ or less and those with a birthweight of $4 \mathrm{~kg}$ or more had higher rates of type 2 diabetes than the others, but the variation in rates across the four birthweight categories was not statistically significant (Table 1). A U-shaped relationship was suggested when birthweight was treated as a continuous measure in kilograms; a quadratic term approached significance $(p=0.08)$ (Table 1). Maternal diabetes was associated with higher mean birthweight of the cohort member $(3.52 \mathrm{~kg}$ compared with $3.39 \mathrm{~kg}$ in members whose mothers were not reported to have diabetes $p=0.001$ ), but the comparable mean birthweights in re- lation to paternal diabetes were not statistically significant ( $p=0.47$ ) (data not shown).

Early age at adiposity rebound was associated with the highest rates of type 2 diabetes, with the trend in type 2 diabetes rates increasing as age at adiposity rebound decreased (test for trend $p=0.002$ ) (Table 1). Cohort members with the earliest adiposity rebound also had the highest mean BMI in adulthood (Fig. 1), the lowest mean weight gain in infancy, lowest mean BMI at 2 years, and highest mean BMI at 11 years (Table 2). Table 2 indicates that our adiposity rebound measure was a good summary measure of growth trajectories in childhood.

In the sex-adjusted model, using the sample with information on birthweight, age at adiposity rebound and all confounding variables (Table 3), those members with an early age at adiposity rebound had an increased rate of type 2 diabetes, and the trend across the four groups was statistically significant, as in the larger sample. After adjusting separately for birthweight, weight at 2 years, father's social class, maternal diabetes and paternal diabetes, the effect of early adiposity rebound remained significant, with estimates for age at adiposity rebound remaining very similar to those in the model adjusted for sex only (Table 3). Similarly, adjustment for own social class or adult height had little impact on the effect of age at adiposity rebound (Table 4). Adjustment for adult BMI considerably reduced the effect of age at adiposity rebound, and the trend was no longer statistically significant $(p=0.1)$ (Table 4$)$. The final model, including all variables considered, showed that adult BMI and maternal and paternal diabetes had strong independent effects on type 2 diabetes rates. In addition there was weaker evidence that weight at 2 years $(p=0.04)$ and possibly adult social class $(p=0.08)$ also influenced rate of type 2 diabetes (Table 5). There was no significant interaction between adiposity rebound and adult BMI $(p=0.6)$. The number of cohort members whose parents had diabetes was too small to calculate interactions between age at adiposity rebound and those variables. Omitting the variables representing maternal and paternal diabetes had little effect on the other variable estimates in the final model.

\section{Discussion}

Young age at adiposity rebound was associated with increased rates of type 2 diabetes with onset between ages 31 and 53 years. The effect of age at adiposity rebound was 


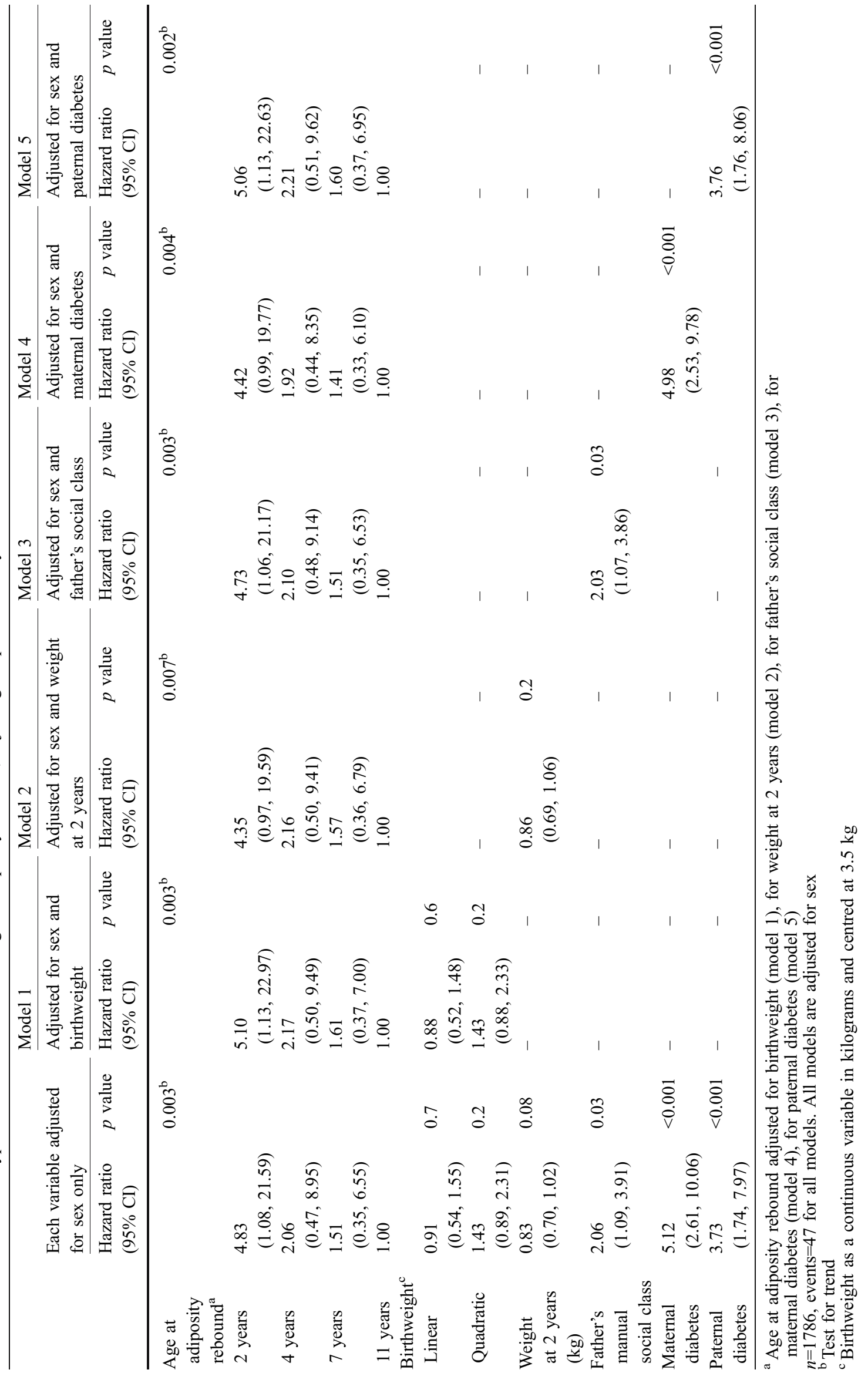


Table 4 Hazard ratios for type 2 diabetes in relation to age at adiposity rebound adjusted for sex and potential adult confounders

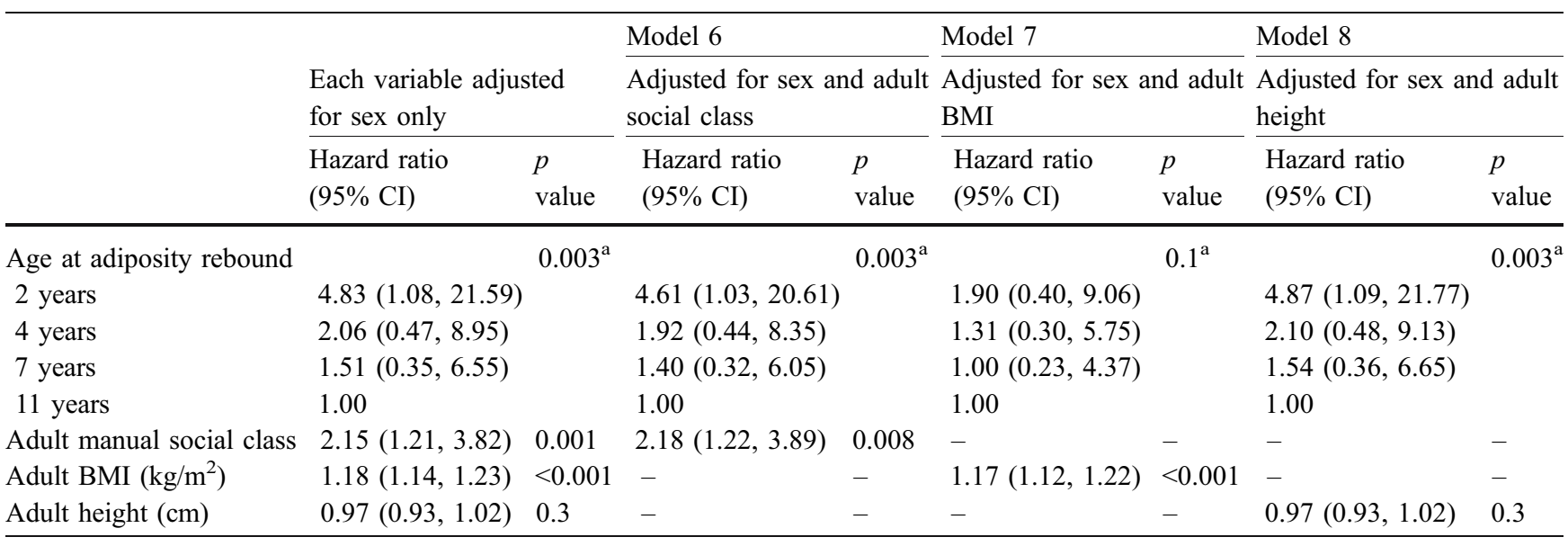

Age at adiposity rebound adjusted for sex and adult social class (model 6), sex and adult BMI (model 7) and sex and adult height (model 8) $(n=1786$, events $=47$ for all models)

a test for trend

considerably weakened, and became no longer significant, after adjustment for adult BMI. In the final mutually adjusted model, adult BMI and parental diabetes were strong effects, and weight at 2 years was marginally significant.

This study has the advantages of a representative sample from the general population, with prospectively collected measures of birthweight, and of height and weight in infancy, childhood, adolescence and adulthood, as well as lifetime indicators of socio-economic position, and reports of parental diabetes. It has the disadvantages of: (1) not knowing how diabetes in cohort members or their parents was treated; (2) not knowing about age at diabetes onset in parents; (3) having self-reported diagnosis of own type 2 and of parental diabetes; and (4) a relatively small number of cases of type 2 diabetes. It also has some disadvantages

Table 5 Fully adjusted model $(n=1786$, events $=47)$

\begin{tabular}{llc}
\hline & Hazard ratio $(95 \% \mathrm{CI})$ & $p$ value \\
\hline Age at adiposity rebound & & \\
2 years & $1.38(0.28,6.79)$ & \\
4 years & $1.26(0.28,5.59)$ & \\
7 years & $0.98(0.22,4.35)$ & \\
11 years & 1 & $0.4^{\mathrm{a}}$ \\
Birthweight & & \\
Linear $(\mathrm{kg})$ & $0.96(0.53,1.71)$ & 0.9 \\
Quadratic $\left(\mathrm{kg}^{2}\right)$ & $1.37(0.82,2.29)$ & 0.2 \\
Female sex & $0.61(0.24,1.56)$ & 0.3 \\
Father's manual social class & $1.13(0.57,2.25)$ & 0.7 \\
Maternal diabetes & $5.95(2.95,11.98)$ & $<0.001$ \\
Paternal diabetes & $4.75(2.18,10.33)$ & $<0.001$ \\
Adult manual social class & $1.73(0.94,3.18)$ & 0.08 \\
Adult BMI $\left(\mathrm{kg} / \mathrm{m}^{2}\right)$ & $1.19(1.14,1.24)$ & $<0.001$ \\
Adult height $(\mathrm{cm})$ & $1.02(0.96,1.07)$ & 0.6 \\
Weight at 2 years $(\mathrm{kg})$ & $0.77(0.60,0.99)$ & 0.04 \\
\hline
\end{tabular}

\footnotetext{
${ }^{a}$ test for trend

${ }^{\mathrm{b}}$ Birthweight as a continuous variable in kilograms and centred at $3.5 \mathrm{~kg}$
}

commensurate with long-term follow-up. Follow-up in adult life was not as good in groups of low socio-economic status or in the obese [12]. Due to incomplete data, only 47 of our 78 cases were used in the adjusted Cox models. Measurement error may have resulted in an underestimation of some of the associations. Birthweight was rounded up to the nearest quarter of a pound, the exact age at adiposity rebound could not be determined, and adult BMI and social class were treated as time-updated covariates, although information on these variables was only available at four time points, rather than at the exact time each case of diabetes was diagnosed.

Our finding that young age at adiposity rebound, before adjustment for adult factors in this British population, could be an important risk factor for type 2 diabetes replicates in most respects those of previous work on an older Finnish population [5], and those of a population-based prospective study of a younger population in India [13]. Age at adiposity rebound is unlikely to be associated with diet [1415], and that is confirmed by our study, since our sample had a very low incidence of childhood obesity [16] as postwartime food rationing was in place until they were 8 years old. Food rationing will also have reduced differences related to socio-economic status in maternal and childhood diets, compared with those differences in subjects born at other times [17]. Our finding that the relationship of early life growth with type 2 diabetes was largely accounted for by current adult BMI is in agreement with one study [18], but not with those of a later one [3]. It is, of course, possible that the processes that determine adiposity rebound occur in the antenatal period, but we have no data to investigate that.

We did not find a significant association between weight at birth and type 2 diabetes, possibly because of a lack of statistical power due to our relatively small number of cases. Our finding of a possible U-shaped association between birthweight and type 2 diabetes is in agreement with some studies $[19,20]$, but most report an inverse relationship (reviewed in [3]). In agreement with Whincup et al (1997) [21], we found that the post-natal growth effect 
was stronger than the pre-natal effect indicated by birthweight. However, adult BMI was the body size measure that had the strongest influence on risk of type 2 diabetes. Early adiposity rebound was a strong determinant of obesity in later life, which, according to Cole [22], is because early age at adiposity rebound identifies children whose BMI centile is high and/or crossing upwards. The two previous studies that investigated the effect of age at adiposity rebound did not adjust for adult body size $[5,13]$. We are cautious about the association between adiposity rebound and risk of adult disease, because the extent to which BMI truly describes adiposity in pre-pubertal years has yet to be resolved. Nevertheless, we conclude that the importance of age at adiposity rebound for risk of type 2 diabetes lies mostly in its association with high BMI throughout life, particularly in adulthood.

There is concern that the numbers of patients diagnosed with type 2 diabetes in England and Wales could increase by more than $40 \%$ by 2023 [23], attributable chiefly to rising obesity. Although in more recently born cohorts increased childhood obesity, and possibly also an earlier mean age of adiposity rebound, may lead to an increased prevalence of adult metabolic syndrome in general [24], that risk may be considerably augmented by the increase in adult obesity in persons born more recently [25].

Acknowledgements This analysis was funded by the Medical Research Council, and data collection at 53 years was by nurses employed by the National Centre for Social Research. We are grateful to colleagues for their comments, and particularly to the cohort members for their long-term participation in this study.

\section{References}

1. Barker DJP, Hales CN, Fall CHD, Osmond C, Phipps K, Clark PMS (1993) Type 2 (non-insulin dependent) diabetes mellitus, hypertension, hyperlipidaemia (syndrome $\mathrm{X}$ ): relation to fetal growth. Diabetologia 36:62-67

2. Hales CN, Barker DJP, Clark PMS et al (1991) Fetal and infant growth and impaired glucose tolerance at age 64. Br Med J 303: 1019-1022

3. Newsome CA, Shiell AW, Fall CHD, Phillips DIW, Shier R, Law CM (2003) Is birth weight related to later glucose and insulin metabolism? - a systematic review. Diabet Med 20: 339-348

4. Fowden AL (1989) The role of insulin in prenatal growth. J Dev Physiol 12:173-82

5. Eriksson JG, Forsen T, Tuomilehto J, Osmond C, Barker DJP (2003) Early adiposity rebound in childhood and risk of Type 2 diabetes in adult life. Diabetologia 46:190-194

6. Rolland-Cachera MF, Deheeger M, Bellisle F, Sepe M, Guilloud-Bataille M, Patois E (1984) Adiposity rebound in children: a simple indicator for predicting obesity. Am J Clin Nutr 39:129-135

7. Hardy R, Wadsworth M, Kuh D (2000) The influence of childhood weight and socioeconomic status on change in adult body mass index in a British national birth cohort. Int J Obes Relat Metab Disord 24:725-734
8. Fall $\mathrm{CH}$ (2001) Non-industrialised countries and affluence. $\mathrm{Br}$ Med Bull 60:33-50

9. Brunner EJ, Marmot MG, Nanchahal K et al (1997) Effect of socioeconomic inequality in coronary risk: central obesity and the metabolic syndrome. Evidence from the Whitehall II study. Diabetologia 40:1341-1349

10. Hypponen E, Davey Smith G, Power C (2003) Parental diabetes and birth weight of offspring: intergenerational cohort study. Br Med J 326:19-20

11. Mitchell BD, Kammerer CM, Reinhart LJ, Stern MP, MacCluer JW (1995) Is there an excess in maternal transmission of NIDDM? Diabetologia 38:314-317

12. Wadsworth MEJ, Butterworth SL, Hardy RJ et al (2003) The life course prospective design; an example of benefits and problems associated with study longevity. Soc Sci Med 57: 2193-2205

13. Bhargava SK, Sachdev HS, Fall CHD et al (2003) Relation of serial changes in childhood body-mass index to impaired glucose tolerance in young adulthood. N Engl J Med 350:865875

14. Dorosty, AR, Emmett PM, Cowin IS, Reilly JJ, and the ALSPAC Study Team (2000) Factors associated with early adiposity rebound. Pediatrics 105:1115-1118

15. Rolland-Cachera MF, Deheeger M, Bellisle F (2001) Early adiposity rebound is not associated with energy or fat intake in infancy. Pediatrics 108:218-219

16. Braddon FM, Rodgers B, Wadsworth MEJ, Davies JMC (1986) Onset of obesity in a 36-year birth cohort study. Br Med J 293:299-303

17. Prynne C J, Paul AA, Mishra GD, Hardy RJ, Bolton-Smith C, Wadsworth MEJ (2002) Socio-demographic inequalities in the diet of young children in the 1946 British birth cohort. Public Health Nutr 5:733-745

18. Lithell HO, McKeigue PM, Berglund L, Mohsen R, Lithell UB, Leon DA (1996) Relation of size at birth to non-insulin dependent diabetes and insulin concentrations in men aged 50 60 years. Br Med J 312:406-410

19. Dabelea D, Pettitt DJ, Hanson RL, Imperatore G, Bennett PH, Knowler WC (1999) Birth weight, type 2 diabetes, and insulin resistance in Pima Indian children and young adults. Diabetes Care 22:944-950

20. Rich-Edwards J, Colditz GA, Stampfer MJ et al (1999) Birth weight and the risk for type 2 diabetes mellitus in adult women. Ann Intern Med 130:278-284

21. Whincup PH, Cook DG, Adshead F et al (1997) Childhood size is more strongly related than size at birth to glucose and insulin level in 10-11-year-old children. Diabetologia 40:319-326

22. Cole TJ (2004) Children grow and horses race: is the adiposity rebound a critical period for later obesity? BMC Pediatrics $4: 1-7$

23. Dobson R (2002) Number of people with diabetes will increase by $40 \%$ by 2023 , says report. Br Med J News Extra section, 8 June 2002

24. Vanhala MJ, Vanhala PT, Keinanen-Kiukaanniemi SM, Kumpusalo EA, Takala JK (1999) Relative weight gain and obesity as a child predict metabolic syndrome as an adult. Int $\mathrm{J}$ Obes Relat Metab Disord 23:656-659

25. Wadsworth MEJ, Butterworth SL, Montgomery S, Ehlin A, Bartley M (2003) Health. In: Ferri E, Bynner J, Wadsworth MEJ (eds) Changing Britain, Changing Lives. Institute of Education Press, London, pp 207-236 